\title{
BMJ Global Health Ophthalmic services during ongoing conflict: the eye health system in Yemen
}

\author{
David McMaster (D) ,' Mahfouth Abdallah Bamashmus ${ }^{2}$
}

To cite: McMaster D, Bamashmus MA. Ophthalmic services during ongoing conflict: the eye health system in Yemen. BMJ Global Health 2019;4:e001743. doi:10.1136/ bmjgh-2019-001743

Handling editor Seye Abimbola

Received 28 May 2019

Revised 14 September 2019

Accepted 21 September 2019
Check for updates

(C) Author(s) (or their employer(s)) 2019. Re-use permitted under CC BY-NC. No commercial re-use. See rights and permissions. Published by BMJ.

${ }^{1}$ University of Nottingham Faculty of Medicine and Health Sciences, Nottingham, UK ${ }^{2}$ Faculty of Medicine and Health Sciences, Sana'a University, Sana'a, Yemen

\section{Correspondence to}

David McMaster;

mzydhm@nottingham.ac.uk

\section{ABSTRACT}

There is little information on the provision of ophthalmic services and the eye health system in Yemen. Using the WHO framework for analysing health systems, we aim to assess what is known about the current eye health system in Yemen with ongoing conflict. Financial constraints, transportation difficulties and security instability are barriers for many of Yemen's people in need of healthcare. The most recent cataract surgical rate reported in 2012 is 2473 operations per million population, with an increase in operations performed in charity eye camps and the private sector. We identify many governorates of Yemen have inadequate ophthalmic resources. We describe the need for short-term solutions to reduce the backlog prevalence of blindness while local infrastructure is rebuilt, and the importance of long-term reconstruction and transition to local ownership with a sustainable workforce and health service as peace is restored.

\section{INTRODUCTION}

The WHO estimates that globally there are 217 million people with moderate to severe vision impairment and 36 million people blind. ${ }^{1}$ An estimated $80 \%$ of all causes of visual impairment are preventable or curable. ${ }^{2}$ The WHO and the International Agency for the Prevention of Blindness (IAPB) launched the Vision $2020^{3}$ initiative with the aim to eliminate avoidable blindness. ${ }^{3}$ The WHO Global Action Plan (GAP) 2014-2019 builds on the Vision $2020^{3}$ initiative, setting up clear targets to reduce the prevalence of avoidable blindness and visual impairment by $25 \%$ by 2019 from the 2010 baseline. The GAP highlights the need for assessment of available resources and current service deficits to provide a basis for improvement to achieve these goals. ${ }^{2}$

The WHO 2017 Yemen Annual Report emphasises how ongoing conflict, impediment to essential medical supplies and blockade of humanitarian aid have led to deteriorating conditions on the ground. ${ }^{4}$ The damaging effects of conflict on the health of a population are well recognised, and while there has been analysis of Yemen's health system before and after escalation of conflict, there is little information regarding provision

\section{Summary box}

Despite ongoing conflict and deteriorating conditions, there have been recent large-scale treatment campaigns to treat the neglected tropical eye diseases trachoma and onchocerciasis in Yemen.

- We analyse the provision of ophthalmic services and the eye health system in Yemen using the WHO framework for analysing health systems, identifying current provision and service gaps.

- We suggest short-term solutions to reduce the backlog prevalence of blindness in areas of Yemen with inadequate ophthalmic services.

- Longer-term reconstruction requires political advocacy, cost-effective solutions and transition to local ownership.

of ophthalmic services. ${ }^{5}$ The objective of this analysis is to assess what is known about the current eye health system in Yemen, with the aim to identify current provision and gaps that will help inform both short-term planning and longer-term reconstruction as peace is restored.

Yemen is a country at the southern end of the Arabian Peninsula and has an approximate population of 28.5 million people. ${ }^{6}$ The conflict in Yemen has its roots in the failure of a political transition following an Arab Spring uprising in 2011. Fighting began in 2014 and escalated in March 2015 as other Arab states became involved. As of July 2019, 24.1 million people are in need of humanitarian assistance. ${ }^{7}$ The Human Development Index in Yemen reached its lowest value (0.452) in 2017, putting Yemen among the 12 lowest countries in the world. ${ }^{8}$ The national poverty rate was last reported in 2014 and estimated to be $48.6 \%$ of the population, and recent welfare analysis suggests that poverty has increased to an estimated $78 \%$ as Yemen's gross domestic product (GDP) has contracted. ${ }^{6}$ The 2016 Global Burden of Disease Study showed that Yemen had the highest years lived with disability (YLDs) rate at 14744 YLDs per 100000 of all 195 countries and territories analysed. ${ }^{9}$ 


\section{ANALYSIS OF EYE HEALTH SERVICES}

The health system in Yemen includes both public and private sectors, with the Ministry of Public Health and Population (MoPHP) operating a three-tiered system of public health facilities. At a primary level there are health units and health centres, while secondary care is delivered in district or governorate hospitals and tertiary care at referral hospitals in the main cities such as Sana'a and Aden, which also offer teaching services. ${ }^{10}$ The MoPHP estimated that in 2014 there were a total of 4270 public health facilities, including 3047 primary health units, 881 health centres, 187 district hospitals and 56 government hospitals distributed across Yemen. ${ }^{11}$ The total estimated number of private facilities in 2014 was 731 private health centres and 181 private hospitals, of which 333 $(46 \%)$ and $62(34 \%)$, respectively, were located in Sana'a City. ${ }^{11}$ The most recent update from the WHO Health Resources Availability Monitoring System indicates that $53 \%$ of Yemen's health facilities are not fully functional, and hospitals in both the private and public sector have shown unacceptable levels of disaster preparedness. ${ }^{12-14}$ When assessing the technical efficiency of health systems in the Middle East and North Africa (MENA) region, Yemen ranks 19th out of 20 countries. ${ }^{15}$ There are 39 Health Cluster partners with active projects supporting primary and secondary healthcare services across the country. The partners include United Nations agencies, international non-governmental organisations (NGOs) and national NGOs, which provide operational support, incentives and training for health workers, as well as medical supplies, reaching a total of 3011 health facilities as of July 2019. ${ }^{16}$

Regular monitoring and evaluation of existing ophthalmic services is essential to achieve the Vision $2020^{3}$ goal of providing equitable distribution of services to eliminate avoidable blindness. Describing specific elements of the health system allows a systematic approach to identifying limitations and where action is needed. The WHO framework for analysing health systems includes leadership and governance, health information systems, health service delivery, health workforce, access to essential medicines and technologies, and health systems financing. Here we analyse these six components with respect to eye health services across Yemen by identifying key indicators using the eye health systems assessment approach. ${ }^{17}$

\section{Governance}

A primary function of government is commitment of adequate resources, effective policy-making, guidance and national planning for the country's health system. Delivery of healthcare comes under the remit of the MoPHP, which holds offices in each of Yemen's governorates, allowing services to be managed locally. There have been concerns of weakness in governance even before fighting broke out, with high levels of public sector corruption which has only worsened in recent years with a significant deterioration in a core centralised health system. ${ }^{5}{ }^{18}$ In 2017 Yemen ranked between $0 \%$ and $6 \%$ of countries worldwide in good governance indicators, and in 2018 was among the five most corrupt countries in the world. $^{8}$

With the collapse of the health system, Yemen has been heavily reliant on international aid. The initial humanitarian response was planned by WHO with Yemen's Ministry of Health and 20 partnering organisations including Médecins Sans Frontières (MSF) ${ }^{19}$ In August 2016 the National Prevention of Blindness Programme for Yemen met with WHO support. The meeting emphasised the problems conflict has caused, with inequitable distribution of eye care services, many eye units shutting down and many ophthalmologists leaving the country. ${ }^{20}$ They concluded a need to increase the cataract surgical rate (CSR) from 2473 to 3500, to expand eye units in additional governorates, develop ophthalmic human resources, pool financial resources and prepare ophthalmic educational materials for the community. ${ }^{20}$ The most recent IAPB - Eastern Mediterranean 2014 Progress Report states that the World Bank, WHO and IAPB are to collaborate on the control of neglected tropical eye diseases in Yemen, including trachoma and onchocerciasis. $^{21}$

\section{Information systems}

Health information is essential to making evidence-based decisions and planning of human resources and equipment. Prior to conflict there were already significant limitations to health information gathering in Yemen. ${ }^{5}$ In January 2017, with WHO support the National Epidemiological Surveillance Programme launched the electronic Disease Early Warning System (eDEWS) in Yemen, allowing surveillance reporting of communicable diseases using mobile phones. ${ }^{22}$ Data from the weekly bulletins of the eDEWS were used to successfully track and identify trends in an outbreak of diphtheria in $2017 / 2018 .{ }^{23}$ This system does not include all of the major causes of vision loss in Yemen but does show promise for future tracking of eye diseases.

Trachoma is the leading cause of infectious blindness in the world, and loss of infrastructure in Yemen has allowed trachoma to thrive. While conflict has prevented surveillance over some rural areas, data collected by Ali Thabit $e t a l^{24}$ and the Global Trachoma Mapping Project estimate 2.5 million people are at risk in Yemen. ${ }^{25}$ This mapping aided a successful large-scale treatment campaign of medicines and equipment following WHO's recommended SAFE strategy (Surgery, Antibiotics, Facial cleanliness and Environmental improvement), highlighting the importance of accurate health information in disease treatment.

\section{Service delivery}

The prevalence of blindness in Yemen is $1.5 \%$, and the leading causes of vision loss include cataract, refractive error, diabetic retinopathy and corneal opacity. ${ }^{20}$ Cataract is a clouding of the eye's lens that can be effectively 


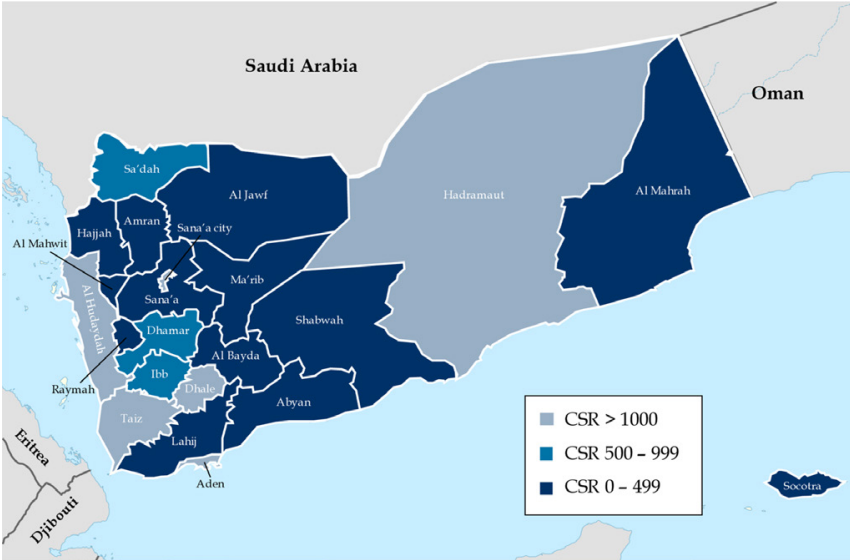

Figure 1 Cataract surgical rate (CSR) in Yemen, 2012. Adapted with permission from Al-Akily et al. ${ }^{26}$

treated with surgery. It is the most common cause of preventable blindness in the world and the leading cause of blindness in both adults and children in Yemen. ${ }^{26-28}$ CSR measures how many cataract operations are performed per million population in a year and gives a useful estimate of ophthalmic service provision. ${ }^{2}$ In 2012 data gathered from government, military, university, private and charity eye clinics across the 22 governorates of Yemen reported a CSR of 2473 operations per million population, an increase from 1560 reported in $2003 .^{26}$ This study also showed that only six governorates had a CSR above 1000, with 13 governorates reporting a CSR of less than 500 (figure 1). ${ }^{26}$ Since 2012 a more recent CSR is yet to be published.

A 2012 survey of 184 eye units across Yemen showed that $61.5 \%$ of cataract operations were performed in the private sector and $16.6 \%$ in charity eye camps, which only make up $2.7 \%$ of the total eye units. ${ }^{29}$ The use of charity eye camps has increased from $9 \%$ of total cataract operations in 2003 to $16.6 \%$ in $2012 .{ }^{30}$ This survey is yet to be repeated and there is also limited information on the number of primary care facilities with dedicated eye care services or the percentage of people living within distance of a functioning facility. Historically Yemen has faced significant challenges to service provision, particularly in rural areas, with approximately $50 \%$ of the population without access to healthcare before escalation of conflict in 2015. ${ }^{51}$ These problems have been exacerbated by targeted attacks on health facilities, roads, the workforce and even international aid, with MSF facilities attacked six times to date. ${ }^{32}$

\section{Workforce}

Developing and maintaining a sustainable workforce are a key part of the GAP, and the ratio of eye health workers to population is a good indicator of progress. The GAP divides human resources into three broad categories, ophthalmologists, optometrists and allied ophthalmic personnel, all of which are essential to an eye health system. The distribution of human resources is also important as often they are concentrated in urban

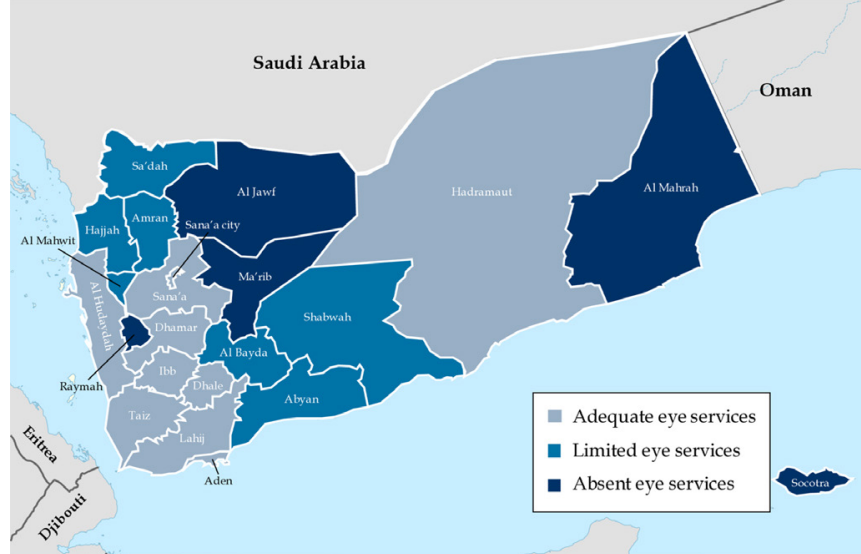

Figure 2 Ophthalmic services provision in Yemen, 2012. Adapted with permission from Al-Akily et al. ${ }^{29}$

centres, leaving rural areas at risk. An example of this is in Enugu State, Nigeria, where the maldistribution of personnel created major barriers to successful treatment despite the overall eye health workforce meeting the WHO standards required to service the population. ${ }^{33}$

In Yemen there had been a marginal increase in the number of ophthalmologists from 2003 to 2012, with 268 ophthalmologists and 72 ophthalmic trainees, a ratio of 1.06 ophthalmologists per 100000 population. ${ }^{29}$ The ophthalmologists were not evenly distributed, with $79.5 \%$ within the governorates of Sana'a, Aden, Taiz and Hadramaut, and no ophthalmologists or eye units in the governorates of Ma'rib, $\mathrm{Al}$ Jawf, $\mathrm{Al}$ Mahrah and Raymah (figure 2). ${ }^{29}{ }^{34}$ In $2012,82.3 \%$ of eye units and $74 \%$ of the 142 ophthalmic operating microscopes in Yemen were located in the governorates of Sana'a, Taiz, Hadramaut and Aden. ${ }^{20} 29$ This survey has not been repeated since, making it difficult to accurately quantify the number of eye health workers still in Yemen, with many likely to have fled the fighting.

\section{Medicines and equipment}

A National Health Policy (last updated in 2010) and a National Medicines Policy (NMP) (last updated 1998) exist in Yemen. The most recent Yemen pharmaceutical profile highlights that neither is structurally implemented nor regularly monitored, with the NMP having no formal implementation plan or clear responsibilities. ${ }^{35}$ The NMP covers areas such as selection of essential medicines, financing, distribution and regulation but does not cover human resource development, rational use of medicines or pharmacovigilance. There is no national adverse drug reaction or pharmacovigilance advisory committee, and Yemen remains in the early stages of developing pharmacovigilance systems and it is not yet a full member of the WHO Collaborating Centre for International Drug Monitoring. ${ }^{36}$

Public sector distribution of medicines involves a central medical store at a national level in Sana'a and four government warehouses located in various governorates. In 2012 there were an estimated 2774 licensed 
pharmacies and 1024 pharmacists (0.4 per 10 000) in Yemen. ${ }^{35}$ A National Essential Medicines List (last updated in 2009) exists, only omitting antivascular endothelial growth factor from the WHO model list of essential ophthalmic medicines. ${ }^{37} 38$

There are no official written guidelines on donations of medicines, and Yemen imposes duties on imported pharmaceuticals. ${ }^{35}$ Humanitarian aid missions have delivered many essential medicines; however, there are no available data on what proportion of ophthalmic medicines and equipment have been delivered and are currently accessible. In May 2018 an international NGO helped distribute more than 444000 doses of azithromycin as well as wash kits and hygiene advice to the rural Al Hudaydah and Ibb regions to treat trachoma. ${ }^{25}$ The WHO led a large-scale treatment campaign in January 2019 delivering 1177524 ivermectin tablets to treat onchocerciasis from the Mectizan Donation Programme in eight governorates. ${ }^{39}$ Heavy fighting in Aden was reported in August 2019, threatening the port of Aden, one of the four logistic hubs for humanitarian aid and the only fully functional port in the country. ${ }^{32}$

In addition to essential medicines and equipment, we assessed the availability of corneal grafts, with corneal opacities one of the most common causes of vision loss in Yemen. ${ }^{27}{ }^{40}$ Due to lack of grafting facilities in Yemen, Al-Akily et $a t^{41}$ reported on corneal grafts performed abroad in countries including Egypt, Jordan and Saudi Arabia between 2001 and 2002. They concluded the need for an eye bank to be established in Yemen; however, a more recent study shows that in 2010 there was still no eye bank and corneal tissue was imported from Tissue Bank International (USA) and the Iran Eye Bank. ${ }^{42}$ Since escalation of conflict there has been no more information regarding the development of an eye bank or the number of facilities that can perform corneal grafting outside of Sana'a.

\section{Finance}

Financing is critical to ensuring health services are provided in a sustainable way, and is usually sourced through taxes, health insurance, user fees and international aid. Public sector funding in Yemen has dramatically fallen in recent years as the economy has contracted and the availability of external loans has reduced. There had been a $46.1 \%$ cumulative decline in GDP during 2015-2018, ${ }^{8}$ and many medical personnel have gone unpaid for almost 2 years. ${ }^{43}$ The out-of-pocket payment as a percentage of total health expenditure is as high as $76 \%$ in Yemen, the joint worst in the MENA region. ${ }^{44}$ High out-of-pocket payments result in people seeking less treatment, selling assets or forgoing other investment, self-medicating with unlicensed unregulated medicines and using traditional healers, who may cause more harm than good.

There has also been persistent underfunding of the humanitarian response to Yemen; the WHO's response plan for 2016 only received $24 \%$ of requested funding. ${ }^{45}$
On 21 August 2019 the United Nations announced that many humanitarian programmes in Yemen are being forced to shut due to lack of funding, with less than half of the original $\$ 2.6$ billion promised for the relief effort received. ${ }^{46}$

As more government eye units have shut down, there has been a rise in use of charity eye camps. A study by Al-Shaer $e t a l^{47}$ assessed factors that influenced patients to attend a free eye camp in Sana'a. Of 284 patients interviewed, $81.7 \%$ attended the free surgery due to financial reasons, $10.2 \%$ due to war and security instability, and $8.1 \%$ due to transportation difficulty. Instability in Yemen has had profound effects on access to healthcare, with $88 \%$ of patients assessed at this free eye camp reporting cataract-related visual problems for more than 6 months; none of the 284 patients presented with a visual acuity of $6 / 60$ or better and $50.4 \%$ were counting fingers in the affected eye. ${ }^{47}$

\section{WHAT CAN BE DONE IN YEMEN?}

Re-establishing the healthcare system in Yemen involves urgent restoration of peace, removal of blockage on imports of essential medicines, improvement of port capacities to receive goods and financial support to relief activities. There are still many unknowns with the eye health system, and while a national survey of functioning eye units may provide this information the need for international aid and short-term to long-term planning in this vulnerable state is already clear.

\section{Short term}

One method of strengthening an eye health system involves integrating ophthalmic services into primary healthcare, allowing prompt detection and equitable referral of individuals with treatable eye conditions. The initial short-term task of reducing the backlog prevalence of blindness as the primary healthcare infrastructure is rebuilt should focus on widening access to eye care services in governorates currently limited (figure 2). Disruption to transport will likely continue long after conflict ends, and with approximately $68 \%$ of the population living in rural areas, outreach programmes must be established to reach these people. We have identified governorates such as Ma'rib, Al Jawf, Al Mahrah and Raymah with historically poor CSR and ophthalmic service provision where relief efforts should begin; however, long-term planning must involve a nationwide approach to ensure no governorates are neglected.

Outreach programmes to rural areas may benefit from deploying well-equipped mobile eye units (MEUs) capable of setting up temporary eye camps offering services such as high-volume cataract surgery to help tackle the initial burden as local eye care services are established. ${ }^{48}$ MEUs are used to deliver eye care to remote locations and have shown their efficacy in disaster relief. ${ }^{49}$ They vary from being equipped to carry out basic ophthalmic examinations and deliver essential medicines to having onboard 
operating theatres. Eye camps are charity-funded temporary screening and treatment centres that provide free eye care at the point of use for those that attend. The primary healthcare facilities available in preconflict Yemen were not optimal for ophthalmic screening and treatment, leading to widespread use of eye camps. ${ }^{50}$ The Al-Nibras Health Society and Taibah Charity Foundation were the first NGOs to hold charity eye camps in Yemen, and between 1999 and 2006 performed 6112 cataract operations. ${ }^{50}$ The Al-Nibras Health Society remains one of the main providers of charity eye camps in Yemen. ${ }^{47}$

Duties and tax can greatly increase the cost of equipment and limit services, particularly when a country relies so heavily on importing medicines. There must be advocacy to waive these fees on essential medicines and equipment as the government begins to restructure. An updated National Health and Medicines Policy with plans for implementation and regular monitoring must be produced, in addition to designing a cost-effective supply system with the aim of increasing constant access to essential medicines.

\section{Medium to long term}

The epidemiology of disease in a country is key to the planning of human resources and equipment. In the medium-term health information systems must be improved with comprehensive national disease surveillance and information on prevalence of visual impairment through methodologies preferred by the GAP, such as a rapid assessment of avoidable blindness survey.

Local eye care services will require a sustainable workforce and sufficient cost-recovery mechanisms to allow continuity of patient care. Rao et a $\tilde{l}^{\tilde{1}}$ demonstrated that high-quality and low-cost eye care can be delivered in rural areas without patients needing to travel great distances and with more than $50 \%$ of services free, while still maintaining self-sustainability by integrating into primary health services. Lessons can be learnt from efforts to rebuild national eye health services in other postconflict zones such as Timor-Leste. ${ }^{52}$ They show how a highvolume intermittent service delivery approach initially focused on local capacity-building rather than infrastructure provision can ensure that donated resources are optimised. The key to long-term rebuilding is transition to local ownership (figure 3), not just with reducing the backlog of disease prevalence, but ensuring guidance into a fully functioning, self-sustaining service with local recruitment and training of eye health workers. Wing et $a \tilde{p}^{2}$ described how they were initially able to mitigate the dearth of subspecialists by inviting visitors to donate their expertise, noting that in the long term this is unsustainable and emphasising the effectiveness of intensive training attachments abroad for local graduates.

As the health of the population recovers, the future challenge for achieving universal eye health coverage will be ongoing treatment of short-term interventions such as cataract and refractive errors, in addition to the control of the growing burden of non-communicable eye diseases in an ageing population. Screening and prevention strategies are required for conditions such as diabetic retinopathy, already one of Yemen's most common causes of vision loss. ${ }^{40} 53$

\section{CONCLUSION}

Assessment of the true impact conflict has on health is difficult, particularly with such a low volume of data generated as conditions have deteriorated. We have analysed the provision of ophthalmic services and the eye health system in Yemen. Financial constraints, transportation difficulties and security instability are acting as barriers for many of Yemen's people, and many governorates of

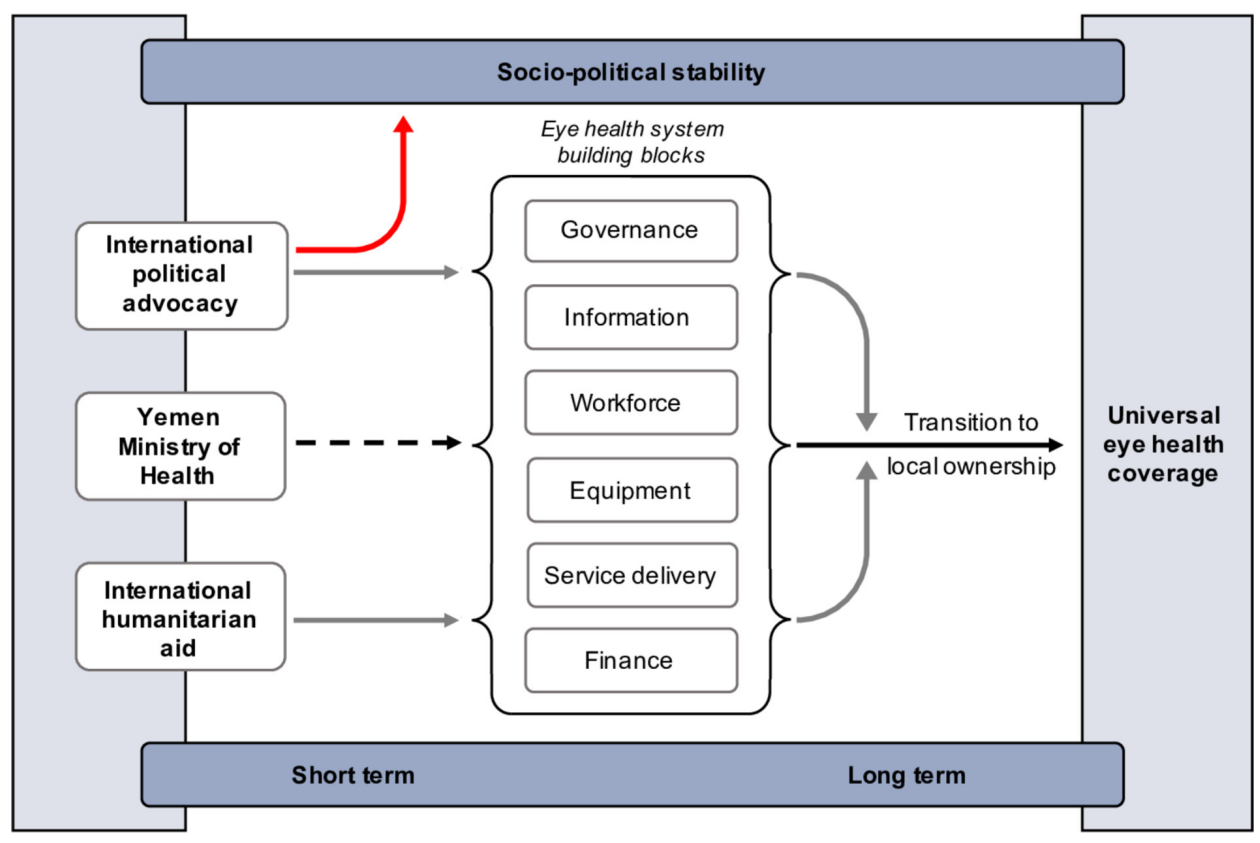

Figure 3 A framework for progression towards universal eye health coverage. 
Yemen have inadequate ophthalmic supplies, equipment and personnel to deliver effective eye care. There must be an initial focused response by international organisations and countries that can offer help to those located in areas of inadequate provision identified here, and then long-term planning to rebuild a broken system. As long as people cannot access ophthalmic services, there will be those needlessly impaired in an already desperate situation, where without sight mortality is inevitable.

Contributors DM performed the literature review, analysis and write-up. MAB reviewed and made changes to the write-up.

Funding The authors have not declared a specific grant for this research from any funding agency in the public, commercial or not-for-profit sectors.

Competing interests None declared.

Patient consent for publication Not required.

Provenance and peer review Not commissioned; externally peer reviewed.

Data availability statement All data relevant to the study are included in the article.

Open access This is an open access article distributed in accordance with the Creative Commons Attribution Non Commercial (CC BY-NC 4.0) license, which permits others to distribute, remix, adapt, build upon this work non-commercially, and license their derivative works on different terms, provided the original work is properly cited, appropriate credit is given, any changes made indicated, and the use is non-commercial. See: http://creativecommons.org/licenses/by-nc/4.0/.

ORCID iD

David McMaster http://orcid.org/0000-0003-1900-8785

\section{REFERENCES}

1 World Health Organisation. World Report on Vision [online]. Available: https://www.who.int/blindness/vision-report/wrv-info/en/ [Accessed 2nd Sep 2019].

2 World Health Organisation. Universal eye health, global action plan 2014-19 [online]. Available: https://www.who.int/blindness/AP2014_ 19_English.pdf [Accessed 13 May 2019].

3 World Health Organisation. What is VISION 2020? [online]. Available: https://www.who.int/blindness/partnerships/vision2020/en/ [Accessed 13 May 2019].

4 World Health Organisation. WHO Annual Report 2017 Yemen [online]. Available: https://www.who.int/emergencies/crises/yem/ yemen-annual-report-2017.pdf [Accessed 13 May 2019].

5 Qirbi N, Ismail SA. Health system functionality in a low-income country in the midst of conflict: the case of Yemen. Health Policy Plan 2017;32:911-22.

6 The World Bank. Poverty \& Equity Brief Middle Republic of Yemen April 2019 [online]. Available: https://databank.worldbank.org/data/ download/poverty/33EF03BB-9722-4AE2-ABC7-AA2972D68AFE/ Global_POVEQ_YEM.pdf [Accessed 2nd Sep 2019].

7 World Food Programme. WFP Yemen Situation Report \#49 July 2019 [online]. Available: https://reliefweb.int/sites/reliefweb.int/files/ resources/WFP\%20Yemen\%20Situation\%20Report\%20\%237\% 2C\%20July\%202019.pdf [Accessed 2nd Sep 2019].

8 Reliefweb. Yemen socio-economic update, Issue 41 - March 2019 [online]. Available: https://reliefweb.int/sites/reliefweb.int/files/ resources/YSEU-41-English.pdf [Accessed 27 Jul 2019].

9 GBD 2016 Disease and Injury Incidence and Prevalence Collaborators. Global, regional, and national incidence, prevalence, and years lived with disability for 328 diseases and injuries for 195 countries, 1990-2016: a systematic analysis for the global burden of disease study 2016. Lancet 2017;390:1211-59.

10 PHRplus. Yemen National Health Accounts: Estimate for 2003 - June 2006 [online]. Available: http://www.phrplus.org/Pubs/ Tech103_fin.pdf [Accessed 27 Jul 2019].

11 The Republic of Yemen Ministry of Public Health \& Population. Annual Statistical Health Report [online]. Available: http://www. mophp-ye.org/arabic/docs/Report2014.pdf [Accessed 27 Jul 2019].

12 World Health Organisation. Health Resources Availability Monitoring System (HeRAMS) [online]. Available: https://www.who.int/hac/ herams/en/ [Accessed 27 Jul 2019].
13 Naser WN, Ingrassia PL, Aladhrae S, et al. A study of hospital disaster preparedness in South Yemen. Prehosp Disaster Med 2018;33:133-8.

14 Aladhrai SA, Djalali A, Della Corte F, et al. Impact of the 2011 revolution on hospital disaster preparedness in Yemen. Disaster Med Public Health Prep 2015;9:396-402.

15 Hamidi S, Akinci F. Measuring efficiency of health systems of the middle East and North Africa (Mena) region using stochastic frontier analysis. Appl Health Econ Health Policy 2016;14:337-47.

16 Health Cluster Yemen. Health Cluster Bulletin July 2019 [online]. Available: http://yemenhc.org [Accessed 2 Sep 2019].

17 International Centre for Eye Health \& London School of Hygiene and Tropical Medicine. Eye Health Systems Assessment (EHSA): How to connect eye care with the general health system, April 2012 [online]. Available: http://blogs.Ishtm.ac.uk/iceh/files/2014/03/Eye-healthsystems-assessment.pdf [Accessed 2 Sep 2019].

18 Transparency International. Yemen [online]. Available: https://www. transparency.org/country/YEM [Accessed 27 Jul 2019].

19 Editorial. Health system in Yemen close to collapse. Bull World Health Organ 2015;93:670-1.

20 World Health Organisation Regional Office for the Eastern Mediterranean. Workshop on national strategy for blindness and visual impairment concludes in Yemen [online]. Available: http:// www.emro.who.int/yem/yemen-events/workshop-on-nationalstrategy-for-blindness-and-visual-impairment.html [Accessed 13 May 2019].

21 International Agency for the Prevention of Blindness (IAPB). IAPB-EMR Progress Report April-September 2014 [online]. Available: https://www.iapb.org/wp-content/uploads/IAPB-EasternMediterranean-Report-September-2014.pdf [Accessed 13 May 2019].

22 World Health Organisation. Regional Office for the Eastern Mediterranean. Electronic integrated disease early warning system launched in Yemen [online]. Available: http://www.emro.who.int/yem/ yemen-news/electronic-integrated-disease-early-warning-systemlaunched-in-yemen.html [Accessed 27 Jul 2019].

23 Dureab F, Al-Sakkaf M, Ismail O, et al. Diphtheria outbreak in Yemen: the impact of conflict on a fragile health system. Confl Health 2019;13:19.

24 Ali Thabit A, Al-Khatib T, Hail WHM, et al. Prevalence of trachoma in Yemen: results of population-based prevalence surveys of 42 evaluation units in nine governorates. Ophthalmic Epidemiol 2018;25:62-9.

25 Sightsavers. First treatments for trachoma distributed in Yemen [online]. Available: https://www.sightsavers.org/news/2018/05/ trachoma-yemen/ [Accessed 13 May 2019].

26 Al-Akily SA, AIShaer MY, Bamashmus MA, et al. Cataract surgical rate in Yemen: 2012. Saudi Journal of Ophthalmology 2017;31:25-9.

27 Al-Akily SA, Bamashmus MA. Causes of blindness among adult Yemenis: a hospital-based study. Middle East Afr J Ophthalmol 2008:15:3.

28 Bamashmus MA, Al-Akily SA. Profile of childhood blindness and low vision in Yemen: a hospital-based study. East Mediterr Health $J$ 2010;16:425-8

29 Al-Akily S, Al-Shaer M, Bamashmus M, et al. Analysis of eye care services in Yemen. Ophthalmology Research: An International Journal 2017;7:1-7.

30 Bamashmus $\mathrm{M}, \mathrm{Al}$-Shaer M, Al-Akily S, et al. Why is cataract surgery Cancelled in eye camps? A prospective evaluation. Saudi J Ophthalmol 2017;9.

31 El Bcheraoui C, Jumaan AO, Collison ML, et al. Health in Yemen: losing ground in war time. Global Health 2018;14:42.

32 Médecins Sans Frontières. Chaos and fighting in Aden as over 50 wounded admitted in just a few hours [online]. Available: https:// www.msf.org/chaos-and-fighting-aden-over-50-wounded-admittedjust-few-hours-yemen [Accessed 2 Sep 2019].

33 Eze BI, Maduka-Okafor FC. An assessment of the eye care workforce in Enugu state, south-eastern Nigeria. Hum Resour Health 2009;7:38.

34 Bamashmus M, Al-Akily S, Al-Barrag A. Human resources and infrastructure for eye care in Yemen: current status. Middle East Afr $\mathrm{J}$ Ophthalmol 2006;13.

35 Ministry of Public Health \& Population of the Republic of Yemen in collaboration with the World Health Organisation. Yemen Pharmaceutical Country Profile [online]. Available: https://www.who. int/medicines/areas/coordination/YemenPSCP_Narrative2012-1216Final.pdf [Accessed 2 Sep 2019].

36 Alshammari TM, Mendi N, Alenzi KA, et al. Pharmacovigilance systems in Arab countries: overview of 22 Arab countries. Drug Saf 2019;42:849-68. 
37 World Health Organisation. WHO Model List of Essential Medicines, 20th List (April 2017) [online]. Available: https://www.who.int/ medicines/publications/essentialmedicines/18th_EML.pdf [Accessed 27 Jul 2019].

38 World Health Organisation Regional Office for the Eastern Mediterranean. List of Essential Medicines in Yemen 15th Edition, October 2009 [online]. Available: http://apps.who.int/medicinedocs/ documents/s21678en/s21678en.pdf [Accessed 27 Jul 2019].

39 World Health Organisation. Despite civil unrest, almost half a million Yemenis treated for onchocerciasis [online]. Available: https://www. who.int/neglected_diseases/news/half-million-Yemenis-treated-foronchocerciasis/en/ [Accessed 13 May 2019].

40 Al-Akily SA, Bamashmus MA, Al-Mohammadi KA. Causes of blindness in people aged 50 years and over: community-based versus hospital-based study. East Mediterr Health J 2010;16:942-6.

41 Al-Akily S, Bamashmus M, Khalifa O. Survival and visual outcome of 70 corneal grafts in Yemeni patients. Saudi J Ophthalmol 2005;19.

42 Bamashmus MA, Al-Akily SA, AlAkhalee HA, et al. Emergency visits after corneal transplantation in Yemen. Oman J Ophthalmol 2017;10:193-7.

43 The Lancet Haematology. The humanitarian cost of Yemen's crumbling health system. Lancet Haematol 2018;5:e599.

44 Asbu EZ, Masri MD, Kaissi A. Health status and health systems financing in the Mena region: roadmap to universal health coverage. Glob Health Res Policy 2017;2.

45 World Health Organisation Regional Office for the Eastern Mediterranean. Health in emergencies update: September-October 2016 [online]. Available: http://reliefweb.int/sites/reliefweb.int/files/ resources/WHO_in_emergencies_October_2016.pdf [Accessed 27 Jul 2019].
46 United Nations Office of the Resident Coordinator and Humanitarian Coordinator for Yemen. Humanitarian programmes in Yemen forced to shut due to lack of funding [online]. Available: https://reliefweb. int/sites/reliefweb.int/files/resources/HC\%20Statement_Sanaa 21August2019_Final.pdf [Accessed 2 Sep 2019].

47 Al-Shaer M, Al-Akily S, Bamashmus M, et al. Factors that enforced patients to attend a free cataract surgery eye cAMP in Yemen. EC Ophthalmology 2018;9:35-41.

48 Venkatesh R, Muralikrishnan R, Balent LC, et al. Outcomes of high volume cataract surgeries in a developing country. $\mathrm{Br} \mathrm{J}$ Ophthalmol 2005;89:1079-83.

49 Yuki K, Nakazawa T, Kurosaka D, et al. Role of the vision van, a mobile ophthalmic outpatient clinic, in the great East Japan earthquake. Clin Ophthalmol 2014;8:691-6.

50 Bamashmus M, Al-Barrag A. Eye camps in Yemen - providing medical coverage to the underprivileged. Med Sci Monit 2008;14:41-5.

51 Rao GN, Khanna RC, Athota SM, Rani P, et al. Integrated model of primary and secondary eye care for underserved rural areas: the L V Prasad eye Institute experience. Indian J Ophthalmol 2012;60:396-400.

52 Wing K, Low G, Sharma M, et al. Building a national eye-care service in post-conflict Timor-Leste. Bull World Health Organ 2018;96:716-22.

53 Bamashmus MA, Gunaid AA, Khandekar RB, et al. Diabetic retinopathy, visual impairment and ocular status among patients with diabetes mellitus in Yemen: a hospital-based study. Indian $J$ Ophthalmol 2009;57:293-8. 